\title{
Determining Learning Techniques by Using Artificial Intelligence and Observing the Impacts of Differentiated Education Model
}

\author{
Ceylin Büyüksoy ${ }^{1}$, Zeynep Taşcıŏglu ${ }^{1}$ and İbrahim Ergin ${ }^{2}$ \\ ${ }^{1}$ FMV Işık High School $10^{\text {th }}$ Grade Student, Turkey \\ ${ }^{2}$ FMV Işı1k High School Chemistry Teacher, Turkey
}

\begin{tabular}{|c|c|}
\hline ARTICLE INFO & ABSTRACT \\
\hline $\begin{array}{l}\text { Keywords: } \\
\text { VAK model } \\
\text { Artificial Intelligence } \\
\text { Effective Learning }\end{array}$ & $\begin{array}{l}\text { It is fundamental for students to be aware of how they acquire } \\
\text { knowledge from resources in the constantly evolving and changing } \\
\text { world. The three most practical senses in learning environments are } \\
\text { sight, hearing and touch. The VAK model categorizes these sensory } \\
\text { methods of learning as Visual (V), Auditory (A) and Kinesthetic (K) } \\
\text { learning styles. In the } 21 \text { st century, it is inevitable to avoid the use of } \\
\text { technology in education. Using ways and technical methods of } \\
\text { technology in the classroom enables teachers and students to find the } \\
\text { new conclusion of daily life problems. It helps in education to create a } \\
\text { better educational syllabus, learning material, and future products and } \\
\text { services. As a conclusion, we have focused on learning techniques by a } \\
\text { specific software that we have written in collaboration with a computer } \\
\text { programmer. By this software, the learning technique of each student } \\
\text { will be analyzed by means of online tests to be performed. At the end of } \\
\text { the day, the learning style of each student will be particularly } \\
\text { understood.After the development of the software, which will last } \\
\text { around } 3 \text { months, we will introduce the new system to the students. } \\
\text { Having finalized the test period, we will measure the success rate of } \\
\text { students in their lessons compared to traditional learning. In this article, } \\
\text { the relation between the effects of differentiated education on academic } \\
\text { achievement with the learning skills of students classified by artificial } \\
\text { intelligence will be studied. }\end{array}$ \\
\hline
\end{tabular}

\section{Introduction}

Knowing yourself as a learner is important if you want to achieve to the best of your ability. When it comes to processing information, your brain is the most important part of your body. It's where all thinking, learning, and decision-making takes place. If you know your learning style, then you can study smarter, not harder. If you know how you learn best, you can also communicate more effectively with your instructor (Hawksworth, 2015).

Carol Ann Tomlinson is a leader in the area of differentiated learning and professor of educational leadership, foundations, and policy at the University of Virginia. Tomlinson describes differentiated instruction as factoring students' individual learning styles and levels of readiness first before designing a lesson plan. Research on the effectiveness of differentiation shows this method benefits a wide range of students, from those with learning disabilities to those who are considered high ability (Weselby, 2018).

The aim of the present article is to observe the impacts of learning techniques on students' success rate by using artificial intelligence and evaluate the outcomes.

* Corresponding Author E-Mail Address: ibrahimrgn@ hotmail.com 


\subsection{Efficient Learning}

Although the term "effective" has been widely used, it only makes sense when context and goals are specified. Effective for who and when? This clarifies the fact that the term 'effective learning' only makes sense when these two aspects are indicated. So, what is effective learning? Effective learning is to gain the understanding of learning how to learn and the necessities for the individual to understand.

Effective learning requires having a variety of strategies and reviewing in order to scope efficiency. The crucial part is that strategies are not effective when they aren't used or integrated into other contexts. When a learner notices, monitors and reviews how his or her learning is going the process becomes automatically more qualified.

Learning about learning or 'meta-learning' is the most important item of effective learning. Metacognition empowers learners to be conscious of their own thoughts. This means that learners are encouraged to reevaluate what they do, say and think. Another aspect is selfregulation that is supported by metacognition. Shanker (2010) has built on the work of Stanley Greenspan and described self-regulation as - "the ability to manage your own energy states, emotions, behaviours and attention, in ways that are socially acceptable and help achieve positive goals, such as maintaining good relationships, learning and maintaining wellbeing. Self-regulation refers to the degree individuals are metacognitively, motivationally and behaviorally active participants in their own learning process (Zimmerman, 1986). Selfregulated learning is an active process in which students establish the objectives leading their learning, try to monitor, regulate and control their thoughts, motivation and behavior in order to accomplish them. (Heikkill \& Lonka, 2006; Nicol\&Macfarlane-Dick,2006). Self-regulated learners can manage their emotional process. By this feature, they can make appropriate decisions and set attainable goals. They make these decisions and set these goals by being aware of their weeknesses, strengths and limitations. Awareness of psychology bears realization of the learning process. Effective learning involves outcomes such as: more connected knowledge, wider range of strategies, greater complexity of understanding, enhanced action appropriate to goals and context, increased engagement and self-direction, more reflective approach, more positive emotions and affiliation to learning, more developed vision of future self as a learner, greater facility in learning with others more sense of participation in a knowledge community.

To conclude; metacognition and self-regulation helps pupils think about their own learning more explicitly by teaching them specific strategies for planning, monitoring and evaluating. These two aspects enhance efficient learning and promotes becoming an autonomous individual.

\subsection{Learning Techniques}

The Information Age has changed people, technology, science, economies, culture, and even the way people think. It also changed the traditional education to modern education. Modern education is mainly online and also very flexible because there is no specific timing or place. In modern education systems learners are expected to possess an increased degree of autonomy and show initiative in learning processes, inspecting learning materials and understanding contents. Not only in modern education but also in traditional education learners have to be aware of their learning process.

The efficient growth of knowledge is only possible when the skills the students acquire initiate and guide them inside and outside school. The received information is also more controllable and easier to internalize when it is integrated into our lives. In studies related to learning and teaching these techniques are called learning strategies.

Learning styles differentiate due to characteristics and preferences of learners. The process of how they acquire information mirrors students' choices, the way they grasp notions and how 
they live in this environment through their experiences. Resolving learning styles strengthens both the atmosphere of the teaching and learning environment and the accuracy of the subjects to be learned inside and outside class. When these learning styles are taken into consideration while teaching, the class environment becomes more interactive and the success rate of the students increase significantly.

To sum up, by the examination of the learning style will raise awareness of how the brain learns best. (Hawksworth,2015) This awareness develops metacognitive and self-regulative skills and helps learners become actively engaged in their learning.

\subsection{VAK Model}

The original VAK concepts were first developed by psychologists and child teaching specialists such as Fernald, Keller, Orton, Gillingham, Stillman and Montessori, starting in the 1920 's. This simple model doesn't overlay either Kolb' theory that says the most effective learning model is the model that carries concrete experience, reflective observation, abstract conceptualizing and active conceptualization (McLeod, 2013) or Gardner's multiple intelligence theory. The VAK learning style uses the three main sensory receivers (Vision, Auditory, and Kinesthetic) to determine a person's dominated or preferred learning style.

Visual learners prefer to learn via the visual channel. Therefore, they like to read a lot, which requires concentration and time spent alone. Visual learners need the visual stimulation of bulletin boards, video and movies. They must have written directions if they are to function well in the classroom". (Oxford, 1995, p. 35) Auditory learners enjoy the oral-aural learning channel. Thus, they want to engage in discussions, conversations, and group work. These students typically require only oral directions". (Oxford, 1995, p. 36) Kinesthetic learners are those who "imply total physical involvement with a learning environment such as taking a field trip, dramatizing, pantomiming, or interviewing" (Kinsella, 1995, p. 172).

As a conclusion, the VAK model is beneficial in education system due to its help in determining the most suitable way of learning. This determination increases learners' concentration, selfdiscipline and ensures the prevention of wasting time and energy. Besides it will improve the communication with the instructor which will have a positive impact on the grades. By the implementation of VAK model an educational field will be created which allows students to study smarter, not harder; unlike what students are asked for at the current system.

\subsection{Differentiated Education}

Carol Ann Tomlinson is a leader in the area of differentiated learning and professor of educational leadership, foundations, and policy at the University of Virginia. Tomlinson describes differentiated instruction as factoring students' individual learning styles and levels of readiness first before designing a lesson plan. Research on the effectiveness of differentiation shows this method benefits a wide range of students, from those with learning disabilities to those who are considered high ability (Weselby, 2014).

The current syllabus in Turkey and the way teachers teach is not differentiated. The teachers set the same task and provide little variations and examples of the topic discussed. They evaluate students' success according to a general criteria and favor only the "gifted students" with diverse methods and activities. In order for students to succeed and develop, teachers should provide a curriculum that adjusts either the content being discussed, the process or the product expected from the learners. Adaptation of the curriculum ensures students at every level to receive the instructions clearly.

If there is a single instructional strategy that has the potential to address the challenges of meeting diverse needs of students in today's inclusive educational settings, Differentiated Instruction (DI) is, perhaps, the one (Logan, 2011). Despite the potential benefits of the strategies of DI in improving student learning, embracing change and adopting such an 
innovation has proven to be challenging for many teachers. There have been reports that implementation of DI strategies in many classrooms are infrequent, inconsistent, and incorrect (Morrison-Thomas, 2016).

So, it is crucial for teachers to provide the most suitable setting for students to learn more efficiently and permanently. The teachers as well as the teaching materials should be defined for each approachment separately. On this basis we performed a study in Iş1k High School to find out which circumstances create these inconsistent learning environments which are poorly constructed for students.

\subsection{Artificial Intelligence}

Rapid innovations in technology, from the rise of the digital age to mobility, is an evidence of how development and experience of science and technology succeeded on its every phase of revolution. We can detect this through our daily life which is constantly adapting to the modifications on technology.

Artificial intelligence (AI) is the ability of a digital computer or computer-controlled robot to perform tasks commonly associated with intelligent beings. The term artificial intelligence is noften applied to the project of developing systems which is also adapted to the common traits of human such as reasoning, discovering meaning and learning from previous occurrences. Starting from the evolution of the digital computer, it has been seen that computers can be set to accomplish complex tasks as playing chess or proving mathematical theorems.

\subsection{The Integration of Artificial Intelligence in Education}

What drives AI's evolution and improvement is the application of simulators and tutorial programs, in addition to various interactive games software developed under an increasingly user-friendly interface. From the infant education level to the highest postgraduate levels, these mechanisms have aspired to adapt to the various needs of students in the first place and keep trying to adapt to the needs depending on 21 st century's innovations and developments. From the beginning of the development of information and communication technologies, differentiated learning utilization is one of the key items AI impacts the education environment. As for the process of personalized education, the AI application can, in a certain way, be considered as a viable solution, since the automated assistance in relation to the students' help (regardless of the level) allows a new and attractive perspective in relation to the learning dynamism, since the virtual interaction, regulated by the AI parameters, facilitates the learning process. The foregoing leads us to rethink about the teaching-learning process, whose impacts of an adaptive education scenario, create a great impact on conventional learning. As new and better applications based on AI are developed, it will be more likely that the new curricula will be versatile and susceptible to an accelerated adaptation in relation to the new and parsimonious ways of understanding educational tasks in this century.

\section{Materials and Methods}

In this experiment we collaborated with an Artificial Intelligence (AI) expert, Ali Büyüksoy launched one of the first hedge funds of Turkey in 2004, Traded as CTA major global macro derivatives since 2008. Currently involved in architecting of electronic trading platforms and in the design and development of pure quantitative and fully automated trading and risk management strategies in major global indices, commodities, stocks and currencies over the last 15 years.

This expert transferred the rules of the test in to a server. Then we had students take this test manually and integrated the results in to our server through $\mathrm{R}$ language. Although this test can be evaluated using more simplistic programs like Excel, the coder preferred " $\mathrm{R}$ " for the reason that this AI can be used for big data in the future and for more complicated evaluations. This 
programme determined the dominant learning technique for each student we have applied the test.

This study used a pretest-posttest control group method as a basis for its design and was carried out in a 8-week time period. As measuring tools, an achievement test and an attitude scale of chemistry were administered to students, as both a pretest and a posttest. During the experiment, their chemistry teachers gave instructions to the groups.

\subsection{Subjects}

The subjects in this study were 82 tenth-grade students (15-16 years of age, in four different classes) from a private high school in Istanbul, Turkey. In this high school, classes are determined according to the students' success rates. One of four classes include students who have high-level academic achievements and these classes are named as High-Level Academic Achievement Class (HLAAC). The other three classes include students who have low level academic achievements and these two classes are named as Low-Level Academic Achievement Class (LLAAC). HLAAC group had 19 students, and the LLAAC 41 students. The control group, on the other hand, had 22 students in the remaining one class.

Chemistry teacher who is co-author of this paper conducted all the lessons for all three groups. Ibrahim ERGIN who is a chemistry teacher and a co-author of article had more than 7 years of teaching experience.

\subsection{Treatment}

Differentiated education methods, based on Visual (V), Auditory (A) and Kinesthetic (K) learning styles, were applied to the experimental groups as teaching methods.

There is widespread belief among educators, as well as the public, that providing instruction based on an individual's preferred learning style improves learning. That is, individuals with a visual learning style preference will comprehend better when they read rather than listen and, conversely, individuals with an auditory learning style preference will comprehend better when they listen rather than read.

However, there has been reports in conflict with widespread belief. Results demonstrated no statistically significant relationship between learning style preferences (auditory, visual word) and learning comprehension based on instructional method (audiobook, e-text).

The Kolb Learning Style Inventory differs from other tests of learning style and personality used in education by being based on a comprehensive theory of learning and development. Experiential learning theory (ELT) draws on the work of prominent twentieth century scholars who gave experience a central role in their theories of human learning and developmentnotably John Dewey, Kurt Lewin, Jean Piaget, William James, Carl Jung, Paulo Freire, Carl Rogers, and others-to develop a holistic model of the experiential learning process and a multilinear model of adult development. The theory, described in detail in Experiential Learning: Experience as the Source of Learning and Development (Kolb 1984), is built on six propositions that are shared by these scholars. (Kolb and Kolb, 2005)

Material designs in terms of learning styles (LS) was an important part of this study because we focused on the impacts of learning styles to academic achievements.

\subsubsection{High Level Academic Achievement Class (HLAAC) Students}

The application steps are presented below:

Step 1 (Teacher Instruction). In the first three lessons of chemistry, given $3 \mathrm{~h}$ a week, the teacher taught the first part of the topic with whole class teaching.

Step 2 (Using Materials). Following the teacher instruction, students were given materials designed in terms of their learning styles (LS) appropriately according to the topic. These materials were classified as Visual (V), Auditory (A) and Kinesthetic (K). These materials 
included 4-5 questions parallel to the subjects. Each student worked on a material individually. During studying materials, students used appropriate materials for them. Each student was expected to give answer for all of the questions on their materials.

Step 3 (Final Evaluation) At the end of the two weeks, the students in the chemistry class took the objective evaluation test. Students' achievements were calculated according to the scores they obtained objective evaluation test.

As a result, a total three chemistry lessons were done in 8 weeks to the HLAAC students. These six lessons included 3 hours of teacher lecturing per two week, two hours of worksheet study which designed for their learning styles (LS).

\subsubsection{Low Level Academic Achievement Class (LLAAC) Students}

All three steps of HLAAC were carried out for LLAAC students. One of the main purposes was observation the change in students' academic achievements between HLAAC and LLAAC.

\subsubsection{Control Group Class (CGC)}

A traditional method was applied for control group students. Lecturing was same as HLAAC and LLAAC in control group class as well. However, worksheets and other materials of control group were different from HLAAC and LLAAC. In control group class (CGC), it wasn't focused on specific learning styles of students. The teacher in control groups used the same materials, and curriculum objectives as in the experimental groups which are HLAAC and LLAAC students. During the application, many problems about subjects were solved in appropriate with course objectives.

\section{Results}

\subsection{HLAAC}

The fact that HLAAC students' academic achievement was high previously, the application of differentiated education did not make a serious increase in the grades. As can be seen in Graph 1, pre-test and pro-test averages of HLAAC students are very close to each other. While the pre-test average of the Visual Students was 89.3, the pro-test average was 89.5. While the average of Visual Students increased by 0.2 points, the average of Auditory Students decreased by 0.2 points. The sharpest increase was observed in the average scores of kinesthetic students. As can be seen from Graph 1, a 0.6 point increase was observed in the average scores of kinesthetic students. According to these results, it was not enough to make a meaningful interpretation and to make a connection between differentiated education and learning styles.

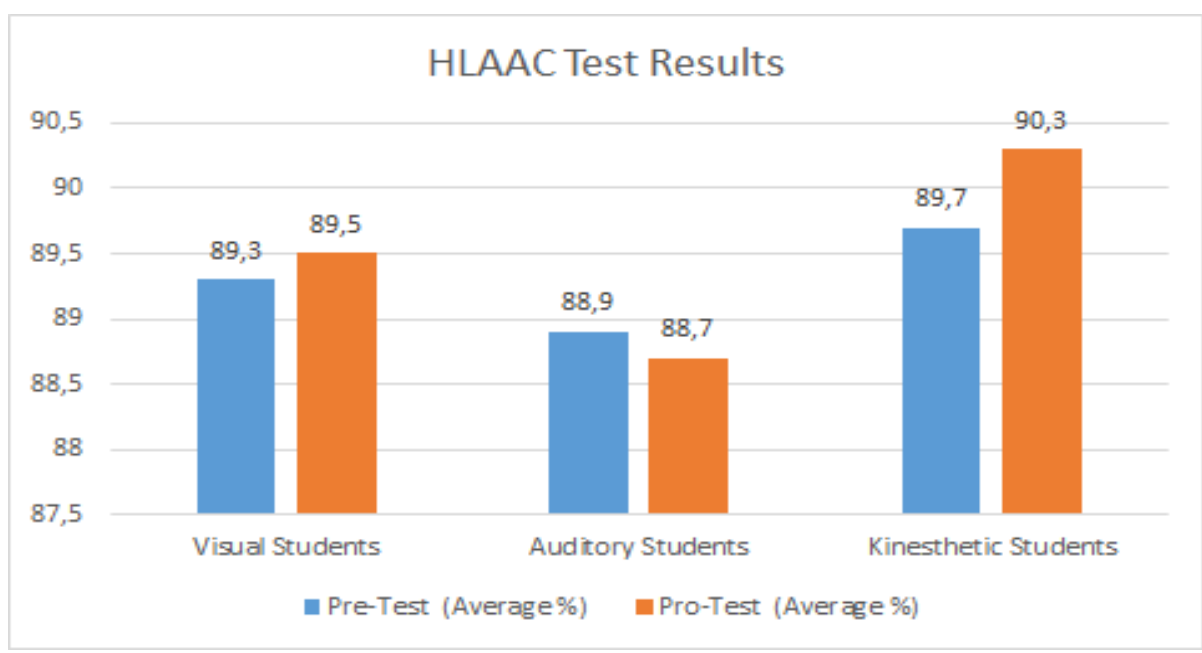

Graph 1. HLAAC Students' score average 


\subsection{LLAAC}

As can be seen from Graph 2, a significant increase was observed in the grade increase of LLAAC students. LLAAC Visual Students had a pre-test average of 62.4. However, the average pro-test applied after differentiated education was 71.1. The increase in the average scores of Visual Students was 8.7. This was only 0.2 for HLAAC Visual Students. Although the LLAAC Auditory Students had a pre-test average score of 63.1, the pre-test average score was 69.9 and an increase of 6.8 points was observed. When the pre-test and post-test averages of the LLAAC Kinesthetic Students were compared, it was observed that these students increased their grades at a higher rate than the others. When HLAAC students and LLAAC students are compared, a significant increase in the average of LLAAC students is observed, whereas HLAAC students do not.

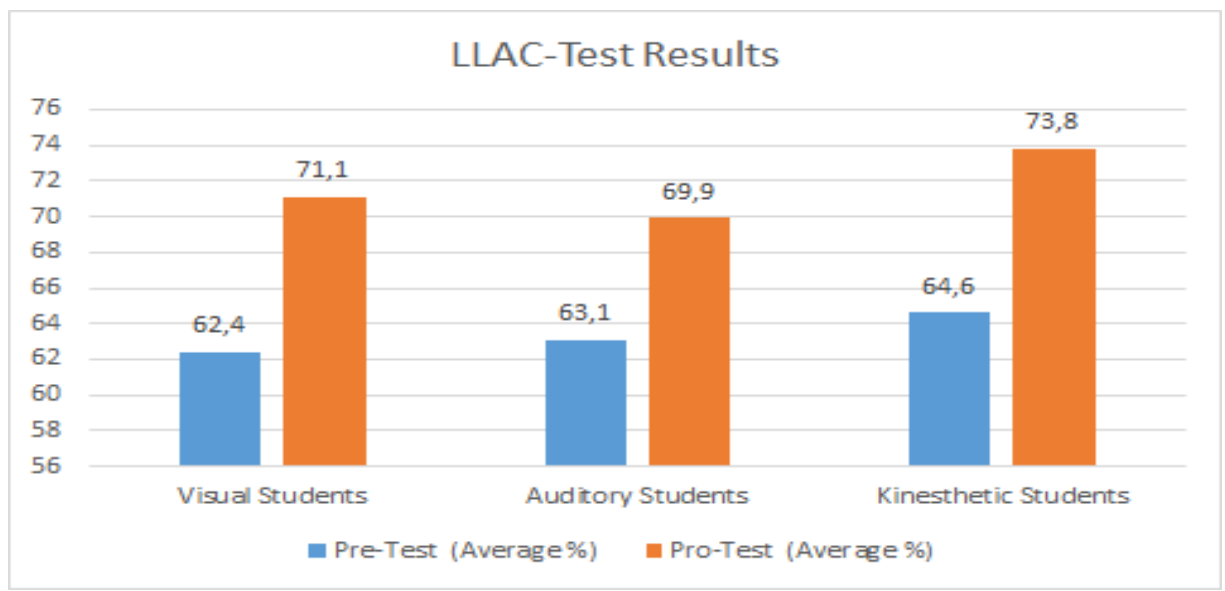

Graph 2. LLAAC Students' score averages

\section{3. $C G C$}

Control Group Class-CGC students were also classified according to their learning styles. However, differentiated education was not applied to these students. As in classical education, teacher-centered education was provided and all students in this class were given one type of document. CGC Visual Students had a pre-test average score of 63.3, and a pro-test average of 67.6. As can be seen in Graph 3, CGC Visual students had an increase like LLAAC students. Although the average pre-test scores of LLAAC students and CGC students were close to each other, the average score increased 8.7 for LLAAC students with differentiated education and it increased for CGC students with classical education increased 4.3. However, when the pro-test results of CGC Auditory Students were examined, no significant increase was observed. Nearly no difference was observed between pre-test and pro-test results. However, there was an increase in LLAAC Auditory Students. While the increase in Visual students is observed, the fact that Auditory students are not observed is an issue that should be investigated. The highest increase among CGC students was observed in Kinesthetic Students. While the pre-test average of CGC kinesthetic students was 61.9, the pro-test average increased by 5.5 points to 67.4. Grade changes of students who have undergone classical education may be another subject that needs to be investigated. 


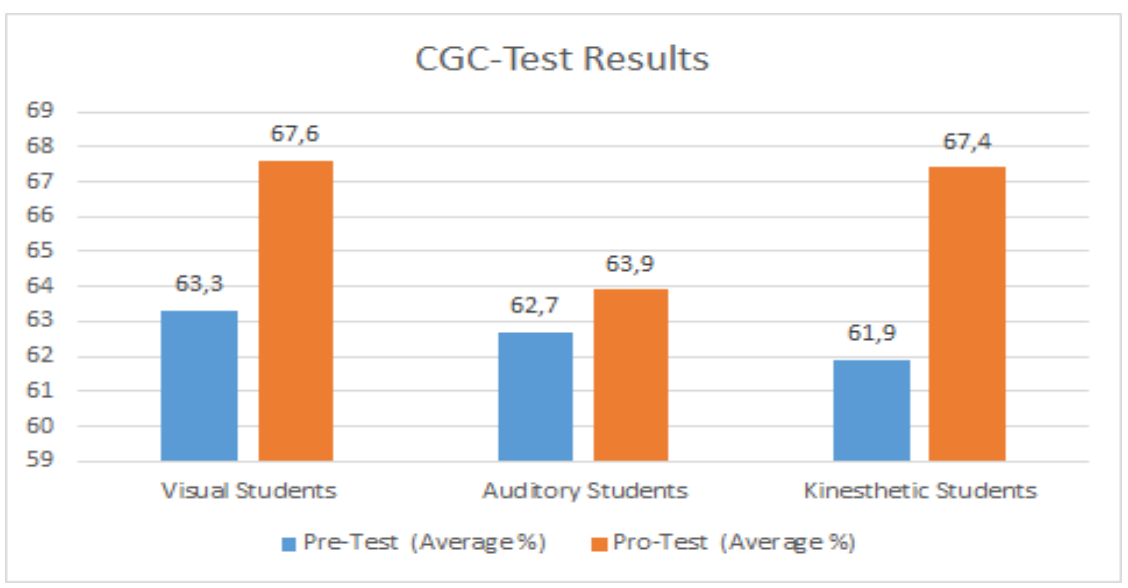

Graph 3. CGC Students' score averages

\section{Discussion}

The study lasted only for 8 weeks and focused only on one unit in the syllabus. This prevented us from making a general assumption. The reason that HLAAC students have high grades in general and that there is no noticeable difference in grades when differentiated education is used. This prevents us from making a clear interpretation.

When interviewed with these students, it can be seen that many of them have positive feedbacks on the differentiated education which has been applied.

LLAAC students are the group that we have observed the most significant changes in average grades. Compared to HLAAC and CGC students, there was a further increase in the average scores of LLAAC students. The most increase was observed in students whose learning styles were kinesthetic. There was only a slight difference between visual and kinesthetic. Compared to CGC students, it can be seen that LLAAC students have increased their grade averages and the differentiated education model applied to this group of students is beneficial. It can be said that with the application of this method many of the students have been affected positively according to the feedback from the students. In fact, some students mentioned that the differentiated education model has increased their interest in the lesson. Taking into consideration that it is an 8-week study, we came to a point that this differentiated education is more suitable for LLAAC students than HLAAC students.

CGC students' grade average increased due to the subject being taught beforehand the pro-test. After the study was completed, differentiated education model was also applied to CGC students as it was applied to other groups. Thus, the education given to the students was prevented from being different and these students had the opportunity to benefit from the same opportunities as the others.

Consequently, we have monitored rise in success level in the LLAAC students that we have applied the test. Even though a rise was expected we still cannot make a general assumption on the success rate of the students. This is because of the limited time and the small number of students who were our testees and finally the fact that there was only one subject that we could apply this test on. Doing long termed observations on learners with an adequate criteria would provide the fundamental context to put this AI based system into action with more precise conclusions.

\section{References}

Bakar, N. A., Shuaibu, A., Bakar R. A. (2017). Correlation of Self-Regulated Learning and Academic Achievement among Universiti Sultan Zainal Abidin (UniSZA) Undergraduate Bakar 254-268. 
Gholami, S., Bagheri, M. S. (2013). "Relationship Between VAK Learning Styles and Problem

" Journal of Language Teaching and Research, 4(4), 700-706 doi:10.4304/j1tr.4.4.700-706

Hawksworth, S. (2015). 'Knowing Your Learning Style Can Help College Success'’ Stanford, The College Puzzle.

IPSP: Inclusion \& Professional Support Program "Self-regulation. A foundation for wellbeing and involved learning.

Kolb, A., Kolb D. (2005). The Kolb Learning Style Inventory. Haygroup,3(1), 1-43.

McLeod, S. A. (2013). Kolb-Learning Styles. Simply Psychology.

Moosa, V., Shareefa, M. (2019). The Impact of Teachers' Experience and Qualification on Efficacy, Knowledge and Implementation of Differentiated Instruction. International Journal of Instruction, 12(2), 2019, 587-604.

Ocana-Fernández, Y., Valenzuela-Fernández, L. A., Garro-Aburto L. L. (2019). Artificial Intelligence and its Implications in Higher Education.Propósitos y Representaciones,7(2), $536-568$.

Rogowsky, B. A., Calhoun B., Tallal P. (2015)"Matching Learning Style to Instructional Method: Effects on Comprehension, Journal of Educational Psychology, 107(1),64-78.

Watkins, C. Carnell, E., Lodge, C., Wagner, P., Whalley, C. (2002). The National School Improvement Network "Effective Learning", Institute of Education University of London.

Weselby, C.(2020).What is Differentiated Instruction? Examples and Strategies, Resilient Educator. 